\title{
ON THE CONCEPTS OF "PRE-PUPA", WITH SPECIAL REFERENCE TO THE COLEOPTERA
}

CLEIDE COSTA SERGIO A. VANIN 2

\begin{abstract}
Three main concepts of "pre-pupa" are recognized here in the Holometabola: i) pre-pupa without a distinct moult bu, with a short quiescent period followed or not by slight modifications of the last larval instar form of body - this type corresponds to the pharate pupa; ii) pre-pupa with a distinct moult, and a quiescent resting period followed by slight form modifications (mainly in the mandibles and color pattern) with a variable period of diapause (ex. Hymenoptera-Symphyta); iii) pre-pupa with a distinct moult, a quiescent period not related to the diapause phenomenon, and distinct morphological modifications (Coleoptera-Mycteridae).
\end{abstract}

\section{INTRODUCTION}

We have been engaged for many years in the study of coleopterous larvae from the Neotropical Region, mainly from Brazil. A great number of larvae were collected and reared. The discovery of the "pre-pupa" phase in the Mycteridae lead us to inquire further about its functions.

Reviewing the bibliography we have noticed that there is little information about the pre-pupa phase. The concepts of "pre-pupa", "pro-pupa" or "pronymph" as an intermediate phase between the last larval instar and the pupa are very old. Moreover, as Heslop-Harrison (1958) pointed out, most of the previous references to this instar do really apply to the pharate phase.

The "pre-pupa", here considered as a quiescent, distinct morphological stage, detected by the presence of a distinct pre-pupal moult, is that observed in the Mycteridae, Coleoptera (Costa \& Vanin, 1977, 1984b). This "intermediate phase" seems to be similar to the so-called "resting stage" of the HymenopteraSymphyta (Krombein et al., 1979).

\section{HISTORICAI}

Poyarkoff (1914) considered the pre-pupa as a case of protothely. Imms (1930) defined the pre-pupa as a stage intermediate between the last larval instar and the pupa, characterized by a brief period of quiescence, during which ecdysis has been suppressed. Comstock (1940), referring to the metamorphosis of Lepidoptera, considered as pre-pupa the period of variable duration "in which the wings are really outside of the body although still covered by the last larval cuticle"; he pointed out that "the pre-pupal instar differs markedly from both the last larval one and from the pupa; for after the shedding of the last larval cuticle important changes in the form of the body take place before the pupal instar is assumed". Heslop-Harrison (1958) presented a broad study of the pre-pupa and pointed out that all previous references to this instar were "applied to the very distinctive pharate phase that exists between the outset of quiescence in the last larval stage and the moult which reveals the external form of the pupa"; he distinguished a pre-

1. Museu de Zoologia, Universidade de São Paulo. With partial aid from "Fundação de Amparo à Pesquisa do Estado de São Paulo" (Proc. 38-Zoologia 81/1932 and 82/2295-8), Pesquisadora do Conselho Nacional de Desenvolvimento Científico e Tecnológico.

2. Departamento de Zoologia, Instituto de Biociências, Universidade de São Paulo. With partial aid from "Fundação de Amparo à Pesquisa do Estado de São Paulo" (Proc. Biológicas $80 / 0540)$. 
pupa, with a distinct pre-pupal moult, from a pre-pupa without a pre-pupal moult. He cited as example of the former many of the Diptera which mou't within a puparium, "in such a fashion as to separate the pharate or plastic condition of the pupal period from that of the non-plastic". He also cited examples within the Hymenoptera-Apocrita (Ichneumonidae) and Symphyta (Chrysididae). Costa \& Vanin observed in Eurypus muelleri (1977) and in Stilpnonotus postsignatus (1984b), both Mycteridae-Coleoptera, a quiescent, distinct morphological stage following the active last larval instar succeeded by a normal pupal instar. It seems to be similar to the "resting stage" of the Hymenoptera-Symphyta, although we have no elements to trace homologies.

\section{DISCUSSION}

We accept here Hinton's $(1946,1973)$ and Heslop-Harrison's views, who considered most of the previous references to the pre-pupa as synonymous of the pharate pupa. We also consider as synonymous of the pharate pupa, the "pre-pupa" of certain Diptera.

In a typical Endopterygota-Holometabola (fig. 7a, adapted from Hinton, 1973) the active last larval instar stops feeding, becomes quiescent and undergoes apolysis, but spends a certain period enclosed within the old larval cuticle. Meanwhile, a progressive morphological change is taking place under the old larval skin. Only after ecdysis, the old skin is shed and the pupa exteriorized. This period of quiescence of the last larval instar is commonly known as "pre-pupa". In certain Coleoptera, for example Euchroma gigantea (Buprestidae) (Costa \& Vanin, 1984a, figs. 2 and 4), the last larval instar at the "pre-pupal period" become shorter, but does not shed its cuticle. Costa (1970) called this period "motionless phase", but it is actually capable of a few movements, like rotation.

In certain Diptera (fig. 7b, adapted from Hinton, 1973) the larval-pupal apolysis is not followed "by a larval-pupal ecdysis, but at emergence the adult sheds both larval and pupal cuticles simultaneously".

In the Mycteridae (Coleoptera-Cucujoidea) (fig. 7c), a distinct extra moult occurs between the active feeding last larval instar and the pupal phase. When the active last larval instar undergoes ecdysis a quiescent phase is originated (figs. 2, 2a, 5). This "intermediate phase" has no external wingpads, resembling more a larva than a pupa. It differs from the feeding stages mainly in the shorter, broader and more cylindrical body shape and in the shape and ornamentations of the ninth abdominal segment. After a short period (in Eurypus and Stilpnonotus, 6-7 days), a new ecdysis takes place and the pupa finally appears.

The presence of this "intermediate phase" between the larval and pupal stages may have two different explanations: 1) it could probably be an autapomorphy of the Mycteridae or at most of a group of families of the Cucujoidea; or ii) it could be a symplesiomorphic character of the Holometabola, the "intermediate phase" of the Mycteridae homologous to that of the Hymenoptera-Symphyta, as far as known, only maintained in these two groups. If this last hypothesis is correct, we must accept the ideas of Poulton (1890), who suggested that "many intermediate stages have been lost between larva and pupa". The "intermediate phase" found in these groups would then be one of such stages lost in the remainder Holometabola. However, the first hypothesis is more parsimonious and seems probably to be the case.

Meanwhile, some considerations must be drawn about the adaptations observed in these two genera of Mycteridae.

Eurypus muelleri (figs. 1-3) has an extremely dorso-ventrally compressed larva, probably related to life in the axils of palm leaves, where the larvae feed (Costa \& Vanin, 1977). The adults are not very flattenêd and do not seem morphologically adapted to live in the same habitat as the larvae; this is supported by the fact that they have never been collected together. Adults have been found climbing on trunk and leaves of palm-trees and also collected at light-traps, thus showing a reasonable flight capacity. When the active feeding last larval instar and the pupa are compared the great differences in 


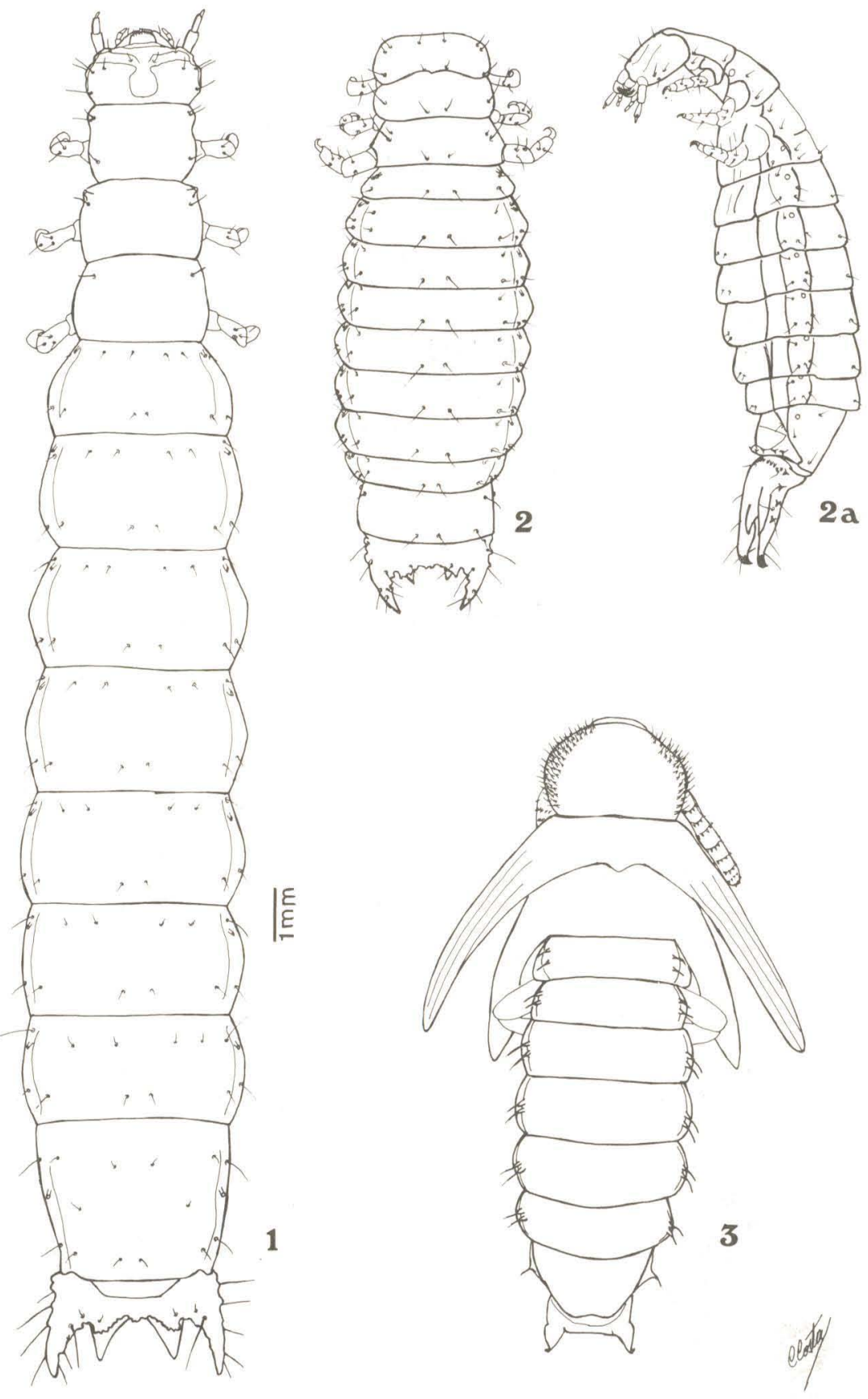

Eurypus muelleri. Fig. 1. mature larva, dorsal view; fig. 2. prepupa, dorsal view; fig. 2a. prepupa, lateral view; fig. 3. pupa, dorsal view. 

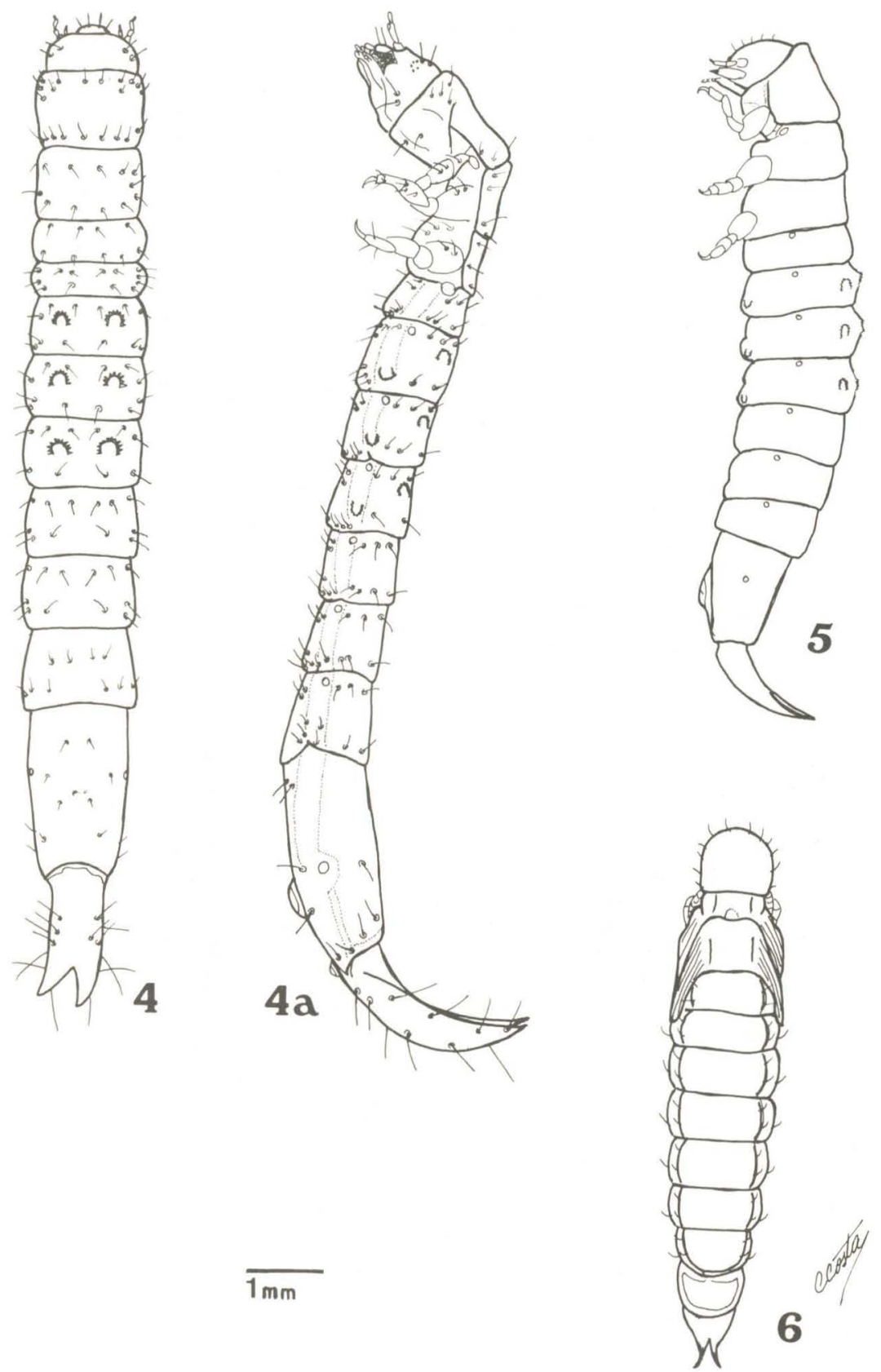

Stilpnonotus postsignatus. Fig. 4. mature larva, dorsal view; fig. 4a. mature larva, lateral view; fig. 5. prepupa, lateral view; fig. 6. pupa, dorsal view. 

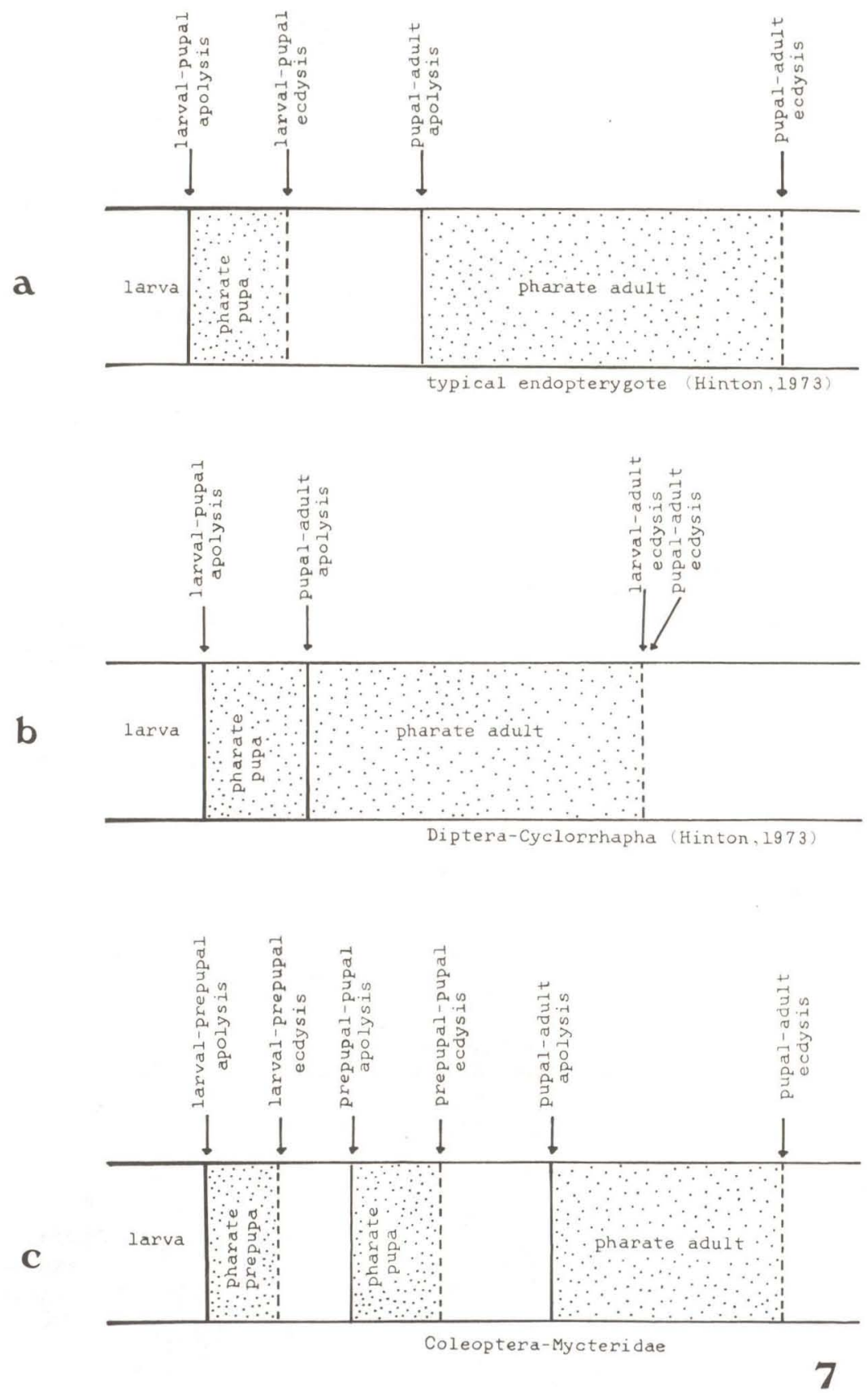

Fig. 7. Variations in the duration of the stages during metamorphosis, showing the "true prepupa" of the Coleoptera-Mycteridae. 
the shape and volume of the thorax in both stages become apparent, the thorax being much smaller in the larva (figs. 1 and 3). Comparing the thorax of the "intermediate phase" with that of the larva and pupa, the differences are not so great.

Stilpnonotus postsignatus (figs. 4-6) has an almost cylindrical larva adapted to burrows in hard wood; it is probably fungivorous (Costa \& Vanin, 1984b). The morphological differences between the thorax of the last larval instar and the adult, although not very striking as in Eurypus, are conspicuous.

One could suggest that the "intermediate phase" in both these species has an important role in the transformations acting on the thorax, mainly in the development of the flight muscles. It could be suggested tha the "intermediate phase" is the result of the morphological differences between larva and adult (chiefly in the case of Eurypus muelleri) but more probably, according to Perez's (1910) ideas, it is the presence of the "intermediate phase" that allowed some larvae of this group to diverge and occupy the most different habitats.

A similar "intermediate phase" occurs among the Hymenoptera-Symphyta. According to Krombein et al. (1979), "after feeding is completed the larva moults into a non-feeding stage called the "pre-pupa" or "resting stage". The pre-pupa normally leaves the host in search of site for pupation . The pre-pupal stage differs morphologically from the feeding stages, especially in the shape of the mandibles and sometimes color pattern". The resting stage may remain in its cocoon for a variable period, depending on the species and other factors.

In the Mycteridae, we have not observed morphological differences in the shape of the mandibles or color pattern. It is similar to the "resting stage" of Symphyta by its non-feeding condition and because it is an intermediate phase between the active last larval instar and the pupa, differing because it is actually a quiescent stage and the cocoon or pupal chamber were prepared by the active last larval instar. Another aspect we must discuss is related with the time the insect remains in this "intermediate phase". In the Hymenoptera-Symphyta this "resting stage" must remain in diapause for weeks, months or years. In the two genera of Mycteridae studied, the "intermediate phase" remains quiescent during 6-7 days before ecdysis; this short time of quiescence cannot be related with the diapause phenomenon.

\section{CONCLUSIONS}

We distinguished here three main types of "pre-pupa" in the Holometabola:

i) pre-pupa without a distinct moult but characterized by a short quiescent period followed or not by some slight body modifications. This type corresponds to the pharate pupa, according to Hinton's concepts. Most of the previous references to the "pre-pupa" phase correspond to this type;

ii) pre-pupa with a distinct moult but characterized by an active "resting stage" which abandons the host in search of a pupation site, followed by a variable period of diapause. There are a few modifications - mainly in the shape of the mandibles and color pattern - between the last larval instar and the "resting stage". This type is found in the Hymenoptera-Symphyta;

iii) pre-pupa with a distinct moult but characterized by a quiescent morphological stage, followed by a very short period (6-7 days) of quiescence before the ecdysis to the pupal stage occurs; is is not related to the diapause phenomenon. This type is known in the Mycteridae-Coleoptera.

The pre-pupa of the Mycteridae is a non-feeding larval stage intercalated between the last active larval instar and the pupal stage. Is is very probably an autapomorphic character of the family not homologous to the similar "resting stage" of the Hymenoptera-Symphyta. The appearance of this character in the Mycteridae seems to be related with its diversified habitats. 
We are grateful to Dr. R. A. Crowson from the Department of Zoology of the University of Glasgow and to our colleagues José H. Guimarães, Nelson Papavero and Dalton de Souza Amorim for reading and commeting the manuscript.

\section{REFERENCES}

Comstock, J. H., 1940. An Introduction to Entomology, 1064 pp. Comstock Publ. Company, Inc. Ithaca, New York.

Costa, C., 1970. Genus Pyrophorus. 3. Life-history, larva and pupa of Pyrophorus punctatissimus Blanchard (Col., Elateridae). Papéis Avulsos Zool., $S$ Paulo 23(8): 69-76.

Costa, C. \& S. A. Vanin, 1977. Larvae of Neotropical Coleoptera. I: Mycteridae, Lacconotinae. Ibidem 31(9): 163-168.

Costa, C. \& S. A. Vanin, 1985a. Larvae of Neotropical Coleoptera. VII: Buprestidae, Buprestinae, Chalcophorini. Ibidem 35(10): 117-124.

Costa, C. \& S. A. Vanin, 1984b. Larvae of Neotropical Coleoptera. X: Mycteridae, Lacconotinae. Revta bras. Zool. 2(2): 71-76.

Heslop-Harrison, G., 1958. On the origin and function of the pupal stadia in Holometabolous Insecta. Proc. Univ. Durham Phil. Soc. (A) 13(8): 59-79.

Hinton, H. E., 1946. Concealed phases in the metamorphosis of insects. Nature, Lond. 157: 552-553.

Hinton, H. E., 1973. Neglected phases in metamorphosis: a reply to V. B. Wigglesworth. J. Ent. (A) 48(1): 57-68.

Imms, A. D., 1930. A general textbook of Entomology, 703 pp. Methuen \& Co. Ltd., London.

Krombein, K. V., P. D. Hurd, Jr., D. R. Smith \& B. D. Burks, 1979. Catalog of Hymenoptera in America North of Mexico, 1: 1198 pp. Smithsonian Institution Press, Washington D. C.

Perez, C., 1910. Signification phylétique de la nymphe chez les insectes métaboles. Bull. scient. Fr. Belg. 44: 221-233.

Poulton, E. B., 1890. The external morphology of the Lepidopterous Pupa: its relation to that of the other stages and to the origin and history of metamorphosis. - Parts. I. - III. Trans. Linn. Soc. London 5(5): 187-212.

Poyarkoff, E., 1914. Essai d'une théorie de la nymphe des insectes Holométaboles. Archs Zool. exp. gén. 54: 221-265. 